\title{
A EFETIVIDADE DE SERVIÇOS PÚBLICOS NA AVALIAÇÃO DE GOVERNO
}

Dissertação de Mestrado

Orientador: Professor Associado Dr. Sérgio Resende de Barros

UNIVERSIDADE DE SÃO PAULO

FACULDADE DE DIREITO

SÃO PAULO - SP 



\title{
A EFETIVIDADE DE SERVIÇOS PÚBLICOS NA AVALIAÇÃO DE GOVERNO
}

\begin{abstract}
Dissertação apresentada à Banca Examinadora do Programa de Pós-Graduação em Direito, da Faculdade de Direito da Universidade de São Paulo, como exigência parcial para a obtenção do título de Mestre em Direito, na área de concentração de Direito do Estado, sob orientação do Professor Associado Dr. Sérgio Resende de Barros.
\end{abstract}

UNIVERSIDADE DE SÃO PAULO

FACULDADE DE DIREITO

SÃO PAULO - SP 
Autorizo a reprodução e a divulgação total ou parcial deste trabalho, por qualquer meio convencional ou eletrônico, para fins de estudo e de pesquisa, desde que citada a fonte.

\section{Catalogação da Publicação \\ Serviço de Biblioteca e Documentação \\ Faculdade de Direito da Universidade de São Paulo}

Rodrigues, Alexandre Peres

A Efetividade de Serviços na avaliação de Governo; Alexandre Peres Rodrigues; orientador Sérgio Resende de Barros -- São Paulo, 2020.

$159 \mathrm{f}$.

Dissertação (Mestrado - Programa de Pós-Graduação em Direito do Estado) - Faculdade de Direito, Universidade de São Paulo, 2020.

1. Serviços Públicos. 2. Avaliação de Governo. 3. Participação do usuário na Administração Pública. 4. Controle Social da Administração Pública. 5. Governabilidade. I. Resende de Barros, Sérgio, orient. II. Título. 


\section{Folha de Aprovação}

RODRIGUES, Alexandre Peres. A Efetividade de Serviços Públicos na avaliação de Governo. Dissertação apresentada à Faculdade de Direito da Universidade de São Paulo para a obtenção do título de Mestre em Direito do Estado, sob a orientação do Professor Associado Sérgio Resende de Barros.

Examinado em:

\section{Banca Examinadora:}

Prof. Dr. Sérgio Resende de Barros Julgamento:

Prof. Dr.

Julgamento:

Prof. Dr.

Julgamento:

Prof. Dr.

Julgamento:
Instituição: Universidade de São Paulo Assinatura:

Instituição:

Assinatura:

Instituição:

Assinatura:

Instituição:

Assinatura: 



\section{DEDICATÓRIA}

Dedico esta obra a Jorge Arantes Peres Rodrigues, vida nova que inspira a nova vida, e a Carolina Pinto Arantes, por nossa velha vida que renova a vida. 



\section{AGRADECIMENTOS}

A trajetória foi longa, árdua e cheia de desafios, e a caminhada só foi possível graças à amizade, valor maior que me auxiliou no fomento da auto superação, da disciplina e da coragem para atender ao desafio.

Em maior ou menor grau, de forma direta ou oblíqua, pelos apontamentos e críticas, todos e todas aqui relacionados são preciosos colabores desta pesquisa.

Agradeço primeiramente ao Professor Sérgio Resende de Barros pela disposição em me receber como seu orientando, por acreditar no potencial da pesquisa e por ceder um pouco da sua grande sabedoria em nossos momentos de debate e orientação.

Logo a seguir, à Beatriz Nimer por todo o apoio, envolvimento e altruísmo. Ao Professor Leonardo Quintiliano, pela disponibilidade, paciência e colaboração. Ao Professor Rubens Beçak pelos preciosos apontamentos na banca de qualificação.

Aos colegas de Mestrado, em especial André Bello e Pedro Casquel, por toda a troca de experiências e fraternidade durante a orientação.

À Professora Eunice Prudente e à Marcia Annunciato, por todos os momentos de aprendizado e humanidade, na monitoria da graduação e em todas as demais prosas.

A Vicente Carrari, Daniel Arbix e Fernando Minchillo por todas as dicas, conselhos e receptividade imensos e efetivos.

À Professora Maria Paula Dallari Bucci, pelas aulas calorosas, assim como às Professoras Mara Regina e Elza Boiteaux, e Professores Conrado Hübner e Masato Ninomiya, pelos aprendizados conquistados.

A Florêncio Penteado e à Roberta Inocêncio, pela crença no potencial da pesquisa. A Cesar Mortari e a Pedro Peruzzo, pelo impulso ao meio acadêmico.

A Gilberto Peres Rodrigues e à Maria Cecília Petrone Peres Rodrigues pela fé e pelo sustento, à Lucy Peres Rodrigues pelo zelo, a Antônio Peres Rodrigues Neto pela rebeldia e a Antônio Peres Rodrigues Filho pelo exemplo. À Carolina e ao Jorge, novamente, pela motivação e pela alegria. 



\section{EPÍGRAFE}

"A maravilhosa beleza das corrupções políticas,

Deliciosos escândalos financeiros e diplomáticos, Agressões políticas nas ruas,

$E$ de vez em quando o cometa dum regicídio

Que ilumina de Prodígio e Fanfarra os céus

Usuais e lúcidos da Civilização quotidiana!

(...)

Amo-vos a todos, a tudo, como uma fera.

Amo-vos carnivoramente,

Pervertidamente e enroscando a minha vista

Em vós, ó coisas grandes, banais, úteis e inúteis,

Ó coisas todas modernas,

(...)

Que importa tudo isto, mas que importa tudo isto Ao fúlgido e rubro ruído contemporâneo,

Ao ruído cruel e delicioso da civilização de hoje?

Tudo isso apaga tudo, salvo o Momento, (...)”

(PESSOA, Fernando. Ode Triunfal - Poema de Álvaro de Campos, 1914).

"The law of progress holds that everything now must be better than what was there before. Don't you see if you want something better, and better, and better, you lose the good. The good is no longer even being measured.".

(ARENDT, Hannah. Entrevista concedida para Roger Errera, New York Review of Books, 1974). 



\section{RESUMO}

\section{RODRIGUES, Alexandre Peres. A Efetividade de Serviços Públicos na avaliação de}

Governo. 159 f. Dissertação (Mestrado) - Faculdade de Direito da Universidade de São Paulo, São Paulo, 2020.

A avaliação de governo é um tema inerente ao bom funcionamento dos estados modernos, já que permite ao cidadão julgar o desempenho político dos governos e o atendimento às diretrizes de Estado, como manifestação de poder frente aos representantes e dirigentes políticos. Ainda que a avaliação contenha um espectro vasto, cuja difusão na sociedade possa ser verificada por outros ramos do conhecimento, o seu estudo jurídico se vale do Direito Constitucional, suas categorias e princípios, de modo que avaliar torna-se tanto condição quanto efeito dos arranjos jurídicos inerentes ao Estado Democrático de Direito. Por outro lado, a atuação dos governos por meio de comodidades e utilidades públicas permite que um dos feixes de avaliação seja realizado através dos serviços públicos, como foco de ações do Estado externalizadas para a população, tanto mais se estes forem conceituados segundo uma acepção específica trazida por um Direito Administrativo constitucionalmente referido, alinhado ao cumprimento dos direitos humanos fundamentais. Nesse sentido, os serviços públicos podem ser qualificados como efetivos se indicarem uma produção real de efeitos práticos, através da adoção de critérios que reafirmem o seu conceito adotado. A efetividade nos serviços públicos subsidia sua avaliação, criando hipóteses de controle social da qualidade do serviço. A percepção vulgar dos serviços públicos pelo cidadão pode transferir a avaliação da qualidade do serviço para o julgamento da atuação dos próprios governos, com reflexos na mensuração da governabilidade e da participação popular na Administração Pública.

Palavras-chave: 1. Cidadania. 2. Governabilidade. 3. Controle Social da Administração Pública. 4. Serviços Públicos. 5. Participação do usuário na Administração Pública. 6. Democracia Participativa. 7. Efetividade. 8. Avaliação de Governo. 9. Direitos Humanos Fundamentais. 10. Estado Democrático de Direito. 



\begin{abstract}
RODRIGUES, Alexandre Peres. The Effectiveness of Public Services on Government Evaluation. 159 f. Dissertation (Master of Law) - Faculdade de Direito da Universidade de São Paulo, São Paulo, 2020.

Government evaluation is a theme inherent to the proper functioning of modern states, as it allows citizens to judge the political performance of governments and its compliance with state guidelines, as a manifestation of power vis-à-vis political representatives and leaders. Although this evaluation contains a wide spectrum, whose diffusion in society can be verified by other branches of knowledge, its legal study wields Constitutional Law, its categories and principles, so that evaluation becomes as much a condition as an effect of legal arrangements arising out of democratic State of Law. On the other hand, government actions through public activities allows one of the evaluation beams to be carried out through public services, as a focus of state actions outsourced to the population, especially if they are conceptualized according to a specific meaning, brought by a constitutionally referred Administrative Law, aligned with the fulfillment of fundamental human rights. In this sense, public services can be qualified as effective if they indicate a real production of practical effects through the adoption of criteria that reaffirm their adopted concept. Effectiveness in public services supports its evaluation, creating means of social control of the quality of public services. The common perception of public services by citizens can expand the evaluation of the quality of services to a judgment of the performance of governments themselves, impacting the measurement of governability and of popular participation in Public Administration.
\end{abstract}

Key Words: 1. Citizenship. 2. Governability. 3. Social Control of Public Administration. 4. Public Services. 5. User participation in Public Administration. 6. Participative Democracy. 7. Effectiveness. 8. Government Evaluation. 9. Fundamental Human Rights. 10. Democratic State of Law. 



\section{ABREVIATURAS E SIGLAS}

$\begin{array}{ll}\text { Art. } & \text { Artigo } \\ \text { Arts. } & \text { Artigos } \\ \text { ADO } & \text { Ação Direta de Inconstitucionalidade por Omissão } \\ \text { ADCT } & \text { Ato das Disposições Constitucionais Transitórias } \\ \text { DASP } & \text { Departamento Administrativo do Serviço Público } \\ \text { DF } & \text { Distrito Federal } \\ \text { DJe } & \text { Diário de Justiça eletrônico } \\ \text { CF/88 } & \text { Constituição Federal da República Federativa do Brasil de } 1988 \\ \text { EC } & \text { Emenda Constitucional } \\ \text { Min. } & \text { Ministro } \\ \text { STF } & \text { Supremo Tribunal Federal }\end{array}$





\section{SUMÁRIO}

INTRODUÇÃ̃...............................................................................................................13

CAPÍTULO I - A AVALIAÇÃO DOS GOVERNOS ...................................................19

1.1 CRITÉRIO ESTÁTICO DE AVALIAÇÃO DE GOVERNO .............................. 24

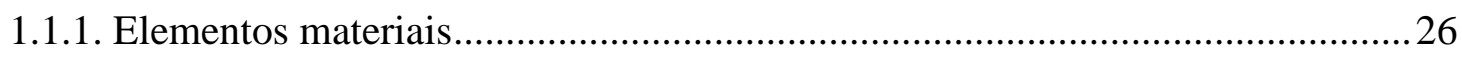

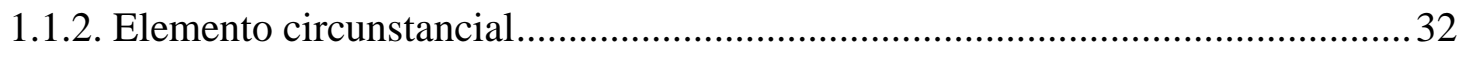

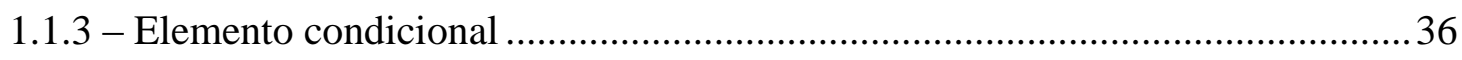

1.2 - CRITÉRIO DINÂMICO DE AVALIAÇÃO DE GOVERNO ............................... 40

1.2.1. Equilíbrio da relação política........................................................................ 41

1.2.2. Governabilidade e relações de poder.............................................................. 44

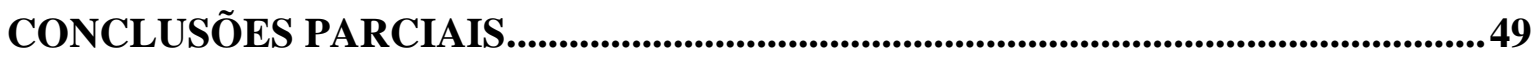

CAPÍTULO II - CONCEITUAÇÃO JURÍDICO-POLÍTICA PARA SERVIÇOS

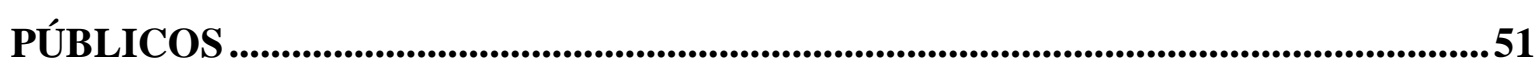

2.1 - EVOLUÇÃO DO CONCEITO DE SERVIÇOS PÚBLICOS ................................54

2.1.1 - A Constitucionalização do Direito Administrativo .........................................61

2.1.2 - Amplitude conceitual de Serviços Públicos ....................................................67

2.2 - EVOLUÇÃO CONCEITUAL NO BRASIL ................................................. 70

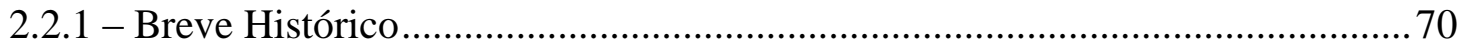

2.2.2 - Os serviços públicos na Constituição Federal de 1988 ................................... 72

2.3 - SERVIÇOS PÚBLICOS CONCEITUADOS SOB A PREMISSA PROPOSTA .. 78

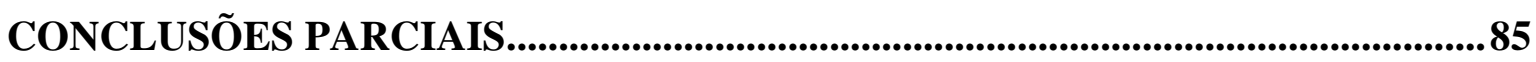





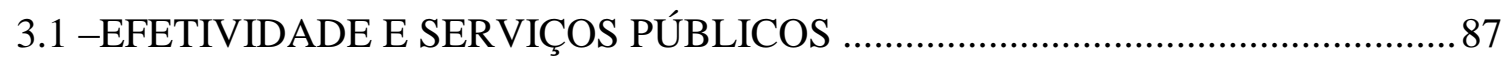

3.2 - RAZÃO DE ESTADO NOS SERVIÇOS PÚBLICOS ....................................... 89

3.2.1 - Serviços Públicos e Direitos Sociais ............................................................. 90

3.3 - A NOÇÃO DE SERVIÇO ADEQUADO...................................................... 101

3.3.1 Princípio da Adequação................................................................................ 104

3.3.2. Adequação como elemento subjacente …..................................................... 110

3.4 - SERVIÇOS PÚBLICOS EM POLÍTICAS PÚBLICAS .................................. 112

CONCLUSÕES PARCIAIS.............................................................................................................117

\section{CAPÍTULO IV - CONTROLE DA GOVERNABILIDADE POR MEIO DOS}

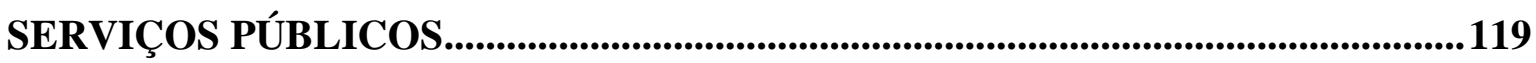

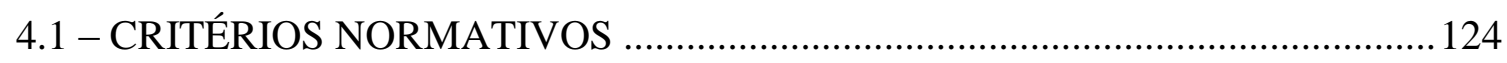

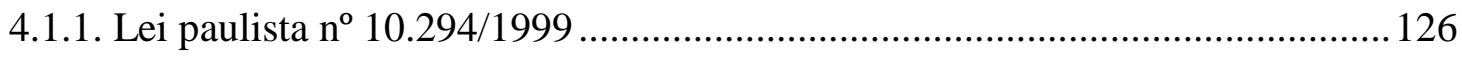

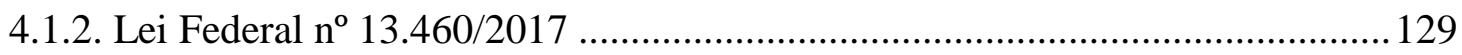

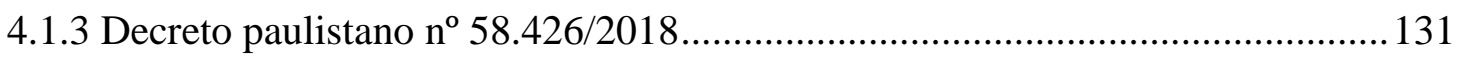

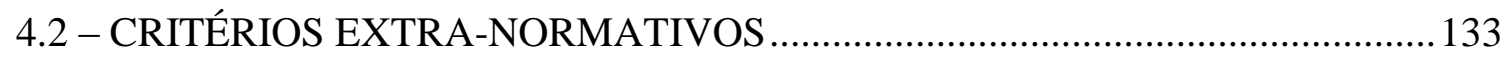

4.2.1 - Serviços Públicos e Democracia Participativa ............................................ 137

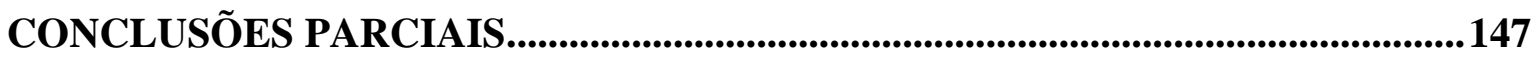

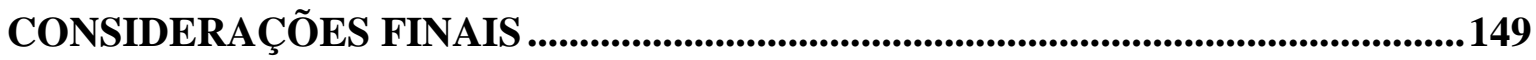

ÍNDICE DAS FONTES ......................................................................................... 151 



\section{INTRODUÇÃO}

No momento em que se iniciava esta pesquisa, as instituições públicas e o ideal de democracia novamente periclitavam, frente a novos - ou velhos-novos - desafios de governabilidade dos governos em exercício. O distúrbio político-social conta com requintes, vez que pode ser apontada uma crise existencial da sociedade política, sobre sua própria razão de ser. Neste compasso, questiona-se a própria legitimação dos poderes públicos, enquanto se estabelece o embate entre as estruturas institucionais postas e os horizontes apresentados pela sociedade da informação, caracterizada pela massificação do consumo, a disseminação de mazelas econômicas e a liquidez das relações sociais. Trata-se de uma complexidade derivada da globalização, que conta com reflexos econômicos e sociais intensos e respostas governamentais nem sempre na mesma magnitude.

Por todo o globo, formas neoliberais de ação, ao lado de movimentos neoconservadores, forçam soluções verticais para a crise e seus efeitos. A convergência dos avanços democráticos do segundo quartil do Século XX passa a ceder espaço para descompassos fáticos que criam dúvidas sobre o enraizamento e permanência das conquistas civilizatórias. De modo formal, as instituições em tese são funcionais, com relativa estabilidade e janelas de saneamento, no entanto surgem cada vez mais manifestações indiciadoras de falhas de uma atuação dos governos em favor dos interesses da população e providentes de uma democracia substancial. Enquanto não se vislumbra resolução próxima para o conflito, há um atordoamento na significação e efetividade dos

próprios direitos humanos, com reflexos na relação do indivíduo para com o Estado a ele conjugado.

No Brasil, a crise político-econômica coloca em xeque os avanços efetuados pela $\mathrm{CF} / 88$. Diversas situações violam ou tendem a violar o conteúdo do pacto político brasileiro, e diferentes visões da crise advogam tanto pela reforma ou fortalecimento das instituições jurídico-políticas, quanto pela sua ruptura. Em ramificações da crise, as políticas públicas em geral vêm sofrendo cada vez mais descontinuidades institucionais, num planejamento míope, um "cinismo" governamental, relativamente aos fundamentos do Estado brasileiro, deturpados em nome de interesses personalistas de indivíduos ou grupos político-econômicos. 
Pode-se afirmar que há uma crise de governabilidade vigente no país, nem tanto pelos episódios de conturbação nos idos de 2015 a 2017, mas principalmente por um descolamento progressivo dos governos e representantes de poder daquilo que a Constituição Federal de 1988 determinou como fundamentos e objetivos do Estado Brasileiro.

Um dos sintomas desta síncope se reflete na prestação e oferta de atividades do Estado para os particulares. Os serviços públicos estão inseridos neste universo, na forma de comodidades públicas que concretizam ações estatais pelo Estado ou quem lhe faça as vezes, emergentes de necessidades fáticas da comunidade para promoção de direitos fundamentais com vistas ao seu bem-estar, sobrevivência e integridade.

Serviços presentes nas diversas esferas de governo pelos mais variados regimes jurídicos e entes públicos apresentam discrepâncias com o seu fundamento legal ou constitucional, já que as prestações colocadas à disposição dos particulares não reverberam o seu objetivo esperado, não criam condições para a sua maturidade fática. Interesses privatistas servem como mote para a descaracterização ou o estocamento de serviços públicos, assim como a flacidez no seu controle e fiscalização periclitam sua qualidade e eficácia; ao fim, este caldo prejudica sua ratio mater de satisfação dos direitos fundamentais correlatos.

A população e os usuários de serviços públicos raramente encontram na prestação de utilidades e comodidades públicas qualquer conformidade a seus direitos fundamentais, qualquer sinal de efetividade dos serviços aos seus fundamentos, tanto mais no decorrer de crises institucionais e escassez de recursos. A efetividade de serviços públicos é um critério que pode vir a favorecer a adesão dos governos aos fundamentos de Estado, conferindo-lhes legitimidade. No entanto, a realidade mostra que, para o cidadão, a figura do Estado é somente uma burocracia coativa, uma estrutura débil, uma espécie de Emplastro Brás Cubas voltado para justificar a própria figura do Estado ou o governo que momentaneamente o titulariza. Não surpreende que os serviços públicos sejam alvo constante de críticas da população e pauta de promessas eleitorais, como eufemismo de uma avaliação da função e da relevância dos governos.

A ingovernabilidade enfeixada para o tema dos serviços públicos resulta na mensuração do grau de afirmação dos poderes constituídos, segundo a efetividade dos serviços prestados ou colocados à disposição dos cidadãos. 
Pretende-se assim questionar como serviços públicos efetivos podem vir a se tornar critérios de avaliação da governabilidade. Desta forma, é possível sintetizar a inquietação desta pesquisa, sumarizada na seguinte sentença: os serviços públicos, caso efetivos, podem servir de critério para a avaliação do governo e medida de governabilidade?

Para esta empreitada, a metodologia a ser adotada envolverá o estudo da doutrina, em cruzamento interdisciplinar de temas, para que sejam afirmadas hipóteses dedutivas voltadas à confirmação de um raciocínio premeditado. A meta é formar premissas que possam confirmar ou não o questionamento levantado, assim como trazer possíveis decorrências desta conclusão.

Preliminarmente, realizar-se-á um estudo sobre o tema da avaliação de governo segundo a ótica do direito constitucional, com abertura para interpretações sistemáticas e principiológicas, ou seja, a Constituição vista como norma-moldura e vetor axiológico de conformação das estruturas e instituições jurídicas. A partir disto, é possível constatar a avaliação de governo como elemento retro alimentador da cidadania, vazante do princípio democrático e resultante da construção do Estado de Direito, o que irradia vetores valorativos para outros ramos jurídicos pares, como o Direito Administrativo. A justificativa para tanto decorre da ausência de dispositivos que verbalizem de maneira explícita e exata uma avaliação em si dos governos, realizadas pelos indivíduos na condição de administrados - e não "eleitores" ou "cidadãos" -, a não ser por decorrência implícita de princípios e teorias, cuja soma possa frutificar em pressupostos lógicos para a verificação da avaliação de governo pelo aporte do direito constitucional.

Em segundo lugar, será necessário adotar um conceito de serviços públicos que dialogue com as premissas levantadas. Para tanto, serão desconsideradas divergências doutrinárias sobre o sentido de serviços públicos para o direito administrativo, preferindose adotar uma noção ampla deste conceito, que não coincida com uma ou outra escola ou corrente de pensamento, mas seja essencialmente funcional em relação às demais premissas desta pesquisa - em especial os temas da governabilidade e da democracia participativa. A funcionalidade reside na análise das prestações estatais voltadas ao particular, num sentido mais fático, real e nem tanto técnico-jurídico. Assim, valoriza-se mais a percepção vulgar e o senso comum do cidadão-administrado sobre o que seria "serviço público" - mais próximo de "atividade pública" - do que construções eminentemente racionais que relacionem conteúdos jurídicos. A justificativa para tanto 
será conformar o sentido específico adotado para serviços públicos com as premissas criadas, em especial pela contribuição do direito constitucional e a incursão do tema da cidadania e da participação do cidadão na Administração Pública.

Em terceiro lugar, adotar-se-á um sentido próprio para o conceito de efetividade, para não se arriscar qualquer confusão com o "princípio da efetividade", o que traria um resultado indesejado nas premissas que o utilizem, já que o sentido de efetividade na pesquisa é guiado e voltado a qualificar o sentido adotado de serviços públicos. Logo, a opção pelo sentido semântico de efetividade afastará análises mais profundas sobre termos próximos, como eficácia e eficiência. Na mesma linha, será adotado um sentido extrajurídico para o conceito de "qualidade nos serviços", já que este dialogará com uma visão ampla de qualidade, além dos dispositivos constantes em lei. Por outro lado, o sentido utilizado de adequação será jurídico, alinhado ao "princípio da adequação", pelos mesmos motivos: a utilização de um sentido não jurídico elasteceria demais o escopo de adequação, alargando-o sobremaneira, o que traria um resultado indesejado para a adequação, que na pesquisa servirá tão somente como um dos critérios de efetividade, não merecendo maiores digressões.

Nesta senda, a opção metodológica interdisciplinar servirá para oxigenar as análises jurídicas, fazendo com que as discussões acadêmicas apresentem o maior diálogo possível com a realidade em seu entorno. Ao abordar uma problemática sob diversos enfoques, a chance de contato com a realidade é muito maior, tanto pela causalidade decorrente da diversidade técnica, quanto pela aderência à complexidade multifocal, plurívoca e abrangente dos fatos. Propõe-se assim a criação de critérios de avaliação bivalentes, os quais tendem a abranger um amplo espectro de possibilidades: estático e dinâmico, dogmático e zetético, prescritivo ou descritivo. A análise fática abrangerá o tema da governabilidade, em uma intersecção com os valores de direitos humanos, medindo a influência das diferentes categorias que compõem o poder na relação política entre governantes e governados, subsidiando uma avaliação relacional e dinâmica, não apenas normativa. O cotejo analítico dos fatos permitirá também a adoção de critérios de efetividade baseados também em critérios extra-normativos, para uma noção geral de adequação e um diálogo com o tema das políticas públicas. Por fim, esta técnica trará elementos para ampliar a análise do controle dos serviços públicos pelo seu usuário, promovendo a intersecção com os temas da democracia participativa e da governabilidade. Desta forma, abre-se caminho para inserir enfoques diversificados no seio do debate da avaliação de governo, costurando temas de direito constitucional e direito administrativo, 
com contribuições da Filosofia do Direito, Filosofia, Sociologia, Direitos Humanos e Teoria Geral do Estado.

Para esta pesquisa, o pareamento de obras doutrinárias será a fonte de pesquisa maior, o que não impede a existência de trechos de citação jurisprudencial como apoio das premissas levantadas ou de raciocínios fundantes das mesmas. Também será feita a interpretação histórica e lógico-sistemática de diplomas normativos, em especial as leis paulistana, paulista e federal sobre o tema de usuário de serviços públicos, as quais contam com escassas referências doutrinárias.

Com todos estes elementos, o objetivo será construir um macrosilogismo tendo por premissa maior a problemática da avaliação de governo e da governabilidade, e por premissas menores os feixes de efetividade dos serviços públicos; como síntese, pretendese enformar a efetividade dos serviços como critério de avaliação dos governos. Possivelmente este é um silogismo de segundo grau, pois pareia tanto macrotemas governabilidade e serviços públicos - quanto se vale de um enfoque oblíquo - democracia e democracia participativa - sobre a reunião destes macrotemas. Ou seja: a análise completa comporta dois sobrevoos - sobre serviços públicos e governabilidade - e a incursão de um tema específico - participação do usuário na Administração Pública como reforço da democracia participativa - para se chegar no resultado desejado. Para atingir este objetivo, serão empregadas técnicas dedutivas, que confrontarão premissas normativas com análises sobre a eficácia social das leis e normas, em especial acerca da efetividade dos serviços públicos e de paradigmas de qualidade destes serviços. Tomando por base esta técnica será possível refletir se as normas existentes no ordenamento carregam em si uma afirmação ou um déficit do controle da qualidade dos serviços pelo seu usuário, e com isso dimensionar os reflexos da governabilidade incidente sobre os serviços públicos, em função da sua efetividade. A partir dessas hipóteses específicas, será criado um padrão para estabilizar a fundamentação lógica das premissas adotadas, reforçando a veracidade das proposições frente aos fundamentos e teorias de apoio.

Esta é a proposta deste estudo, que será estruturado conforme segue.

O "Capítulo I" tratará especificamente da avaliação de governo, trazendo os nexos de apreciação do seu objeto pelos critérios da constituição e da governabilidade. Para isso, haverá um percurso sobre as relações políticas e as categorias formadoras do poder, o fundamento humanista da ordem jurídica pelos pactos de direitos humanos e os reflexos político-jurídicos advindos do Estado Democrático de Direito. 
Prosseguindo para o "Capítulo II", serão trazidos estudos do Direito Administrativo relativos ao tema dos serviços públicos, para formar seu conceito ajustado ao planejamento da pesquisa. Neste ponto, será feita a abordagem tradicional do tema, com a trajetória histórica deste conceito, seguindo rumo a visões contemporâneas, através das quais o instituto será abordado sob outros olhares, em especial pelo filtro constitucional do Direito Administrativo, subordinado aos princípios e regras constitucionais, como fontes emanadoras de preceitos essenciais e porta de entrada para valores e fundamento humanista de ordem jurídica. Com isso, tem-se presente a vertente do Direito Administrativo reagente ao administrado, por meio da qual se busca maior interação com o indivíduo e uma legitimidade ampla dos arranjos administrativos. Deste modo, será visitada a visão de serviços públicos voltada ao seu usuário, contemplando a participação do administrado nos rumos da Administração Pública.

Em continuidade à conceituação de serviços públicos segundo o enfoque específico proposto, o "Capítulo III” dedicar-se-á para a estruturação da efetividade nos serviços. Para isso, o conceito adotado no capítulo anterior será qualificado como "efetivo" caso atenda a critérios cuja gênese ecoe as seguintes proposições: eficácia social dos serviços públicos, adesão destes aos seus fundamentos legais e uma visão fenomênica dos serviços. A abordagem será esquematizada, respectivamente, pelos seguintes temas: atendimento aos direitos humanos fundamentais, noção de adequação dos serviços públicos e correspondência dos serviços com políticas públicas.

Concluindo a pesquisa, o "Capítulo IV" será destinado a confrontar as premissas anteriores, ou seja, a avaliação de governo e os serviços públicos, os quais, transmutados pelos filtros da pesquisa, envolverão por fim os temas de governabilidade e efetividade. Como síntese das premissas, atingir-se-á o controle da qualidade do serviço público pelo seu usuário, através de paradigmas normativos de controle da qualidade, assim como direções para a formação de paradigmas extra normativos. Esta segunda camada terá o apoio da noção de democracia participativa como veículo de alimentação de avaliação dos governos por meio dos serviços públicos efetivos, voltados ao seu usuário. 


\section{CONSIDERAÇÕES FINAIS}

A avaliação de governo pelo cidadão deriva do modelo de Estado Democrático de Direito, tendo por referencial a constituição e por modelo a ideia de governabilidade, a qual abrange a dinamicidade presente nas relações políticas entre governantes e governados.

Os serviços públicos vistos sob ao arcabouço da constituição devem servir para a concretização de direitos humanos fundamentais, permitindo desta forma a adoção de um conceito de serviços públicos voltado ao seu usuário, substrato para a participação deste na Administração Pública.

Serviços públicos tornam-se efetivos se contiverem em si formas de promoção de eficácia social, por alguns critérios tais como: a aderência a fundamentos constitucionais e legais coordenados com a razão de Estado e uma noção geral de adequação, assim como pela sua presença em políticas públicas constitucionalmente referidas.

A governabilidade aplicada aos serviços públicos efetivos pode ser mensurada pelo controle da qualidade dos serviços pelo seu usuário, o que pode ser feito por conteúdos presentes em algumas leis e diplomas normativos específicos sobre o regime jurídico dos usuários de serviços, assim como por uma noção geral e abrangente de qualidade dos serviços públicos, derivada da ideia de democracia participativa.

Os serviços públicos qualificados como efetivos podem ser instrumento de avaliação do governo pelo cidadão e usuário dos serviços através da governabilidade incidente no controle da qualidade dos serviços realizada por critérios normativos e pela incursão da democracia participativa nas atividades públicas prestadas aos particulares. 


\section{ÍNDICE DAS FONTES}

\section{REFERÊNCIAS BIBLIOGRÁFICAS}

AGUILLAR, Fernando Hellen. Controle Social de Serviços Públicos. São Paulo: Max Limonad, 1999.

ALMEIDA, Fernando Dias Menezes de. Contratos Administrativos. In: JABUR, Gilberto Haddad; PEREIRA JUNIOR, Antônio Jorge (coord.). Direito dos Contratos II. São Paulo: Quartier Latin, 2008.

AMARAL, Antônio Carlos Cintra do. Concessão de Serviço Público. $2^{\mathrm{a}}$ ed. São Paulo: Malheiros, 2002.

ARISTÓTELES. Política. Tradução de Pedro Constantin Tolens.. $5^{\mathrm{a}}$ ed. São Paulo: Martin Claret, 2010.

ARAGÃO, Alexandre Santos de. Direito dos Serviços Públicos. $2^{\mathrm{a}}$ ed. Rio de Janeiro: Forense, 2008.

ARENDT, Hannah. A condição humana. 10ª ed. São Paulo: Manole, 2005.

BARROS, Sergio Resende de. A Eficácia dos Direitos Humanos. In: COSTA, José Augusto Fontoura; ANDRADE, José Maria Arruda de; MATSUO, Alexandra Hery Hansen (orgs.). Direito: teoria e experiência: estudos em homenagem a Eros Roberto Grau, Tomo I. São Paulo: Malheiros, 2013.

. Contribuição dialética para o constitucionalismo. Campinas: Millennium, 2007.

. Direito do Consumidor e Geração de Direitos, in Revista de Direito do Consumidor, v. 40, São Paulo: RT, 2002.

2003.

Direitos Humanos: Paradoxo da Civilização. $1^{\mathrm{a}}$ ed. Belo Horizonte: Del Rey,

. Essência e Aparência. In: BEÇAK, Rubens; NIMER, Beatriz Lameira Carrico; QUINTILIANO, Leonardo David (orgs.). Princípios Constitucionais - Contribuições à Luz da Obra de Sérgio Resende de Barros. Belo Horizonte: Arraes, 2018.

Os direitos humanos na história. In: FERRAZ JUNIOR, Tércio Sampaio (org.). Filosofia, sociedade e direitos humanos: ciclo de palestras em homenagem ao professor Goffredo Telles Jr. Barueri: Manole: 2012.

BASTOS, Celso Ribeiro. Curso de Direito Constitucional. 22a ed. São Paulo: Saraiva, 2001 .

Existe efetivamente uma Constituição Econômica? In: BARROSO, Luis Roberto; CLÉVE, Clermerson Merlin (orgs.). Doutrinas Essenciais de Direito Constitucional. Volume VI - Constituição Financeira, Econômica e Social. São Paulo: Revista dos Tribunais: 2013. 
BEÇAK, Rubens. Democracia: hegemonia e aperfeiçoamento. São Paulo: Saraiva, 2014.

BEÇAK, Rubens; CAPUCELLI, Rodrigo Crepaldi Perez. O constitucionalismo Democrático no Brasil: entre a crise da representatividade e a participação. In: Revista Brasileira de Filosofia do Direito, Maranhão, v.3, n.2, Jul/ Dez/2017.

BINENBOJM, Gustavo. Temas de Direito Administrativo e Constitucional - Artigos e pareceres. Rio de Janeiro: Renovar, 2008.

BITTAR, Eduardo Carlos Bianca. Curso de Filosofia Politica. $4^{\mathrm{a}}$ ed. São Paulo: Atlas, 2011.

BITTAR, Eduardo Carlos Bianca; ALMEIDA, Guilherme Assis de. Curso de Filosofia do Direito. $7^{\mathrm{a}}$ ed. São Paulo: Atlas, 2009.

BOBBIO, Norberto. O Futuro da Democracia: uma defesa das regras do jogo. Tradução de Marco Aurélio Nogueira. Rio de Janeiro: Paz e Terra, 1997.

BOITEUX, Elza Antônia Pereira Cunha, A Constante Axiológica dos Direitos Humanos. In: BENEVIDES, Maria Victoria de Mesquita; BERCOVICI, Gilberto; MELO, Claudineu de (orgs.). Direitos Humanos, Democracia e República: Homenagem a Fabio Konder Comparato. São Paulo: Quartier Latin, 2009.

BONAVIDES, Paulo. A Constituição Aberta: temas políticos e constitucionais da atualidade, com ênfase no Federalismo das Regiões. $3^{\text {a }}$ ed. São Paulo: Malheiros, 2004.

BRASIL, Presidência da República. Plano Diretor da Reforma do Aparelho do Estado. Brasília: 1995.

BRASIL, Supremo Tribunal Federal. ADO 24 / DF. Relatoria Min. DIAS TOFFOLI. DJe 018, de 31/01/2018.

BRASIL. Tribunal de Contas da União. Dez passos para a boa governança. Brasília: TCU, Secretaria de Planejamento, Governança e Gestão, 2014.

BUCCI, Maria Paula Dallari. Direito Administrativo e Políticas Públicas. São Paulo: Saraiva: 2006.

BULOS, Uadi Lamêgo. Constituição Federal Anotada. $8^{a}$ ed. São Paulo: Saraiva, 2008.

CAMPILONGO, Celso Fernandes. Direito e diferenciação social. São Paulo: Saraiva, 2011.

O Direito na Sociedade Complexa. São Paulo: Max Limonad, 2000.

CAMPOS, Luiza Ferreira, JUST, Gustavo. Transformação do discurso administrativista: a assimilação das formas argumentativas "pós-positivistas" e as tentativas de redefinição de institutos-chave do direito administrativo. In: MARRARA, Thiago (org.) Direito Administrativo: transformações e tendências. São Paulo: Almedina, 2014. 
CANOTILHO, J.J. Gomes. Direito Constitucional e Teoria da Constituição. $7^{\mathrm{a}}$ ed. Coimbra: Almedina, 2003.

CARDOSO, Fernando Henrique. Mensagem ao Congresso Nacional, abertura da $1^{a}$ Sessão Legislativa Ordinária da 50 Legislatura. Brasília: Presidência da República, Secretaria de Comunicação Social, 1995.

CHEVALLIER, Jean Jacques. As grandes obras politicas de Maquiavel a nossos dias. Tradução de Lydia Christina. $7^{a}$ ed. Rio de Janeiro: Agir, 1995.

CRETELla JUNIOR, José. Dos Contratos Administrativos. Rio de Janeiro: Forense, 1997.

DALLARI, Dalmo de Abreu. Elementos de Teoria Geral do Estado. $28^{\mathrm{a}}$ ed. São Paulo: Saraiva, 2009.

DI PIETRO, Maria Sylvia Zanella. Direito Administrativo. $32^{\mathrm{a}}$ ed. Rio de Janeiro: Forense, 2019.

DUGUIT, Léon. Fundamentos do Direito. Tradução de Márcio Pugliesi. São Paulo: Martin Claret, 2009. Inquérito, 1950.

Os Elementos do Estado. Tradução de Eduardo Salgueiro. Lisboa: Editorial

DWORKIN, Ronald. Levando os direitos a sério. Tradução Nelson Boeira. $3^{a}$ ed. São Paulo: Martins Fontes, 2010.

FARIA, José Eduardo. O direito na economia globalizada. São Paulo: Malheiros, 2004.

FERRAZ JUNIOR, Tércio Sampaio. Introdução ao Estudo do Direito - Técnica, Decisão e Dominação. $4^{\mathrm{a}}$ ed. São Paulo: Atlas, 2003.

FIGUEIREDO, Lucia Valle. Curso de Direito Administrativo. $9^{\mathrm{a}}$ ed. São Paulo: Malheiros, 2008.

FERREIRA FILHO, Manoel Gonçalves. Curso de Direito Constitucional. 40a ed. São Paulo: Saraiva, 2015. . Estado de Direito e Constituição. São Paulo: Saraiva, 1988.

FREITAS, Juarez. Direito Constitucional à Democracia. In: FREITAS, Juarez; TEIXEIRA, Anderson V. (orgs.). Direito à Democracia: ensaios transdisciplinares. São Paulo: Conceito Editorial, 2011.

GOFFI, Ana Maria; SCARTEZZINI, Flaquer. O princípio da Continuidade do Serviço Público. São Paulo: Malheiros, 2006.

GORDILLO, Agustín A. Ideias sobre Participation em American Latina. In: DI PIETRO, Maria Sylvia Zanella; SUNDFELD, Carlos Ari. Doutrinas Essenciais: Direito Administrativo, Volume III: Controle da Administração, Processo Administrativo $e$ Responsabilidade do Estado. São Paulo: RT, 2013. 
Participatión Administrativa. In: DI PIETRO, Maria Sylvia Zanella; SUNDFELD, Carlos Ari. Doutrinas Essenciais: Direito Administrativo, Volume III: Controle da Administração, Processo Administrativo e Responsabilidade do Estado. São Paulo, RT: 2013.

GRAU, Eros Roberto. A Ordem Econômica na Constituição de 1988. 19a ed. São Paulo: Malheiros, 2018.

Constituição e Serviço Público. In: GRAU, Eros Roberto; GUERRA FILHO, Willis Santiago (org). Direito Constitucional: estudos em homenagem a Paulo Bonavides. $1^{\mathrm{a}}$ ed. $2^{\mathrm{a}}$ tiragem. São Paulo: Malheiros, 2003.

GROTTI, Dinorá Adelaide. O Serviço Público e a Constituição Brasileira de 1988. São Paulo: Malheiros, 2003.

GRUNE, Carmela. Participação cidadã na gestão pública: a experiência da Escola de Samba de Mangueira. São Paulo: Saraiva, 2012.

HABERLE, Peter. A sociedade aberta dos intérpretes da Constituição: Contribuição para a interpretação pluralista e procedimental da Constituição. Tradução de Gilmar Ferreira Mendes. Porto Alegre: Editor Sérgio Antônio Fabris, 1997.

HACHEM, Daniel Wunder. Direito fundamental ao serviço público adequado $e$ capacidade econômica do cidadão: repensando a universalidade do acesso à luz da igualdade material. A\&C - Revista de Direito Administrativo \& Constitucional, Belo Horizonte, ano 14, n. 55, p. 123-158, jan./mar. 2014.

INSTITUTO ANTONIO HOUAISS DE LEXICOGRAFIA (org). Pequeno Dicionário Houaiss da língua portuguesa. São Paulo: Moderna, 2015.

ISSACHAROFF, Samuel. Fragile Democracies: Contested Power in the Era of Constitucional Courts. Nova Iorque: Cambridge University Press, 2015.

JUSTEN FILHO, Marçal. Conceito de interesse público e a personalização do Direito Administrativo, Revista Trimestral de Direito Público 26, São Paulo, 1999.

. Curso de Direito Administrativo. 10ª ed., São Paulo: Revista dos Tribunais, 2014.

KELSEN, Hans. Teoria pura do Direito. Tradução João Baptista Machado. $6^{a}$ ed. São Paulo: Martins Fontes, 1998.

KLEIN, Aline Lícia; MARQUES NETO, Floriano de Azevedo. Funções Administrativas do Estado. In: DI PIETRO, Maria Sylvia Zanella (coord.). Tratado de Direito Administrativo - Volume 4. São Paulo: RT, 2015.

LAFER, Celso. Hannah Arendt: pensamento, persuasão e poder. $2^{\mathrm{a}}$ ed. São Paulo: Paz e Terra, 2003. 
LIMA, João Alberto de Oliveira; NICOLA, João Rafael Nicola; PASSOS, Edilenice. A gênese do texto da Constituição de 1988. Brasília: Senado Federal, Coordenação de Edições Temáticas, 2013.

LOEWENSTEIN, Karl. Teoría de la constitución. Tradução Alfredo Gallego Anabitarte. Barcelona: Ariel, 1964.

MAROLLA, Eugênia Cristina Cleto. Concessões de serviço público: a equação econômico financeira dos contratos. São Paulo: Verbatim, 2011.

MARTINS, Ives Gandra da Silva. Teoria sobre as Teorias da Constituição. In: MARTINS, Ives Gandra da Silva; MENDES, Gilmar Ferreira; NASCIMENTO, Carlos Valder do. (Orgs). Tratado de Direito Constitucional - volume 1. São Paulo: Saraiva, 2010.

MEDAUAR, Odete. Direito Administrativo Moderno. 16ª ed. São Paulo: RT, 2012. . O Direito Administrativo em Evolução. $2^{\mathrm{a}}$ ed. São Paulo: RT, 2003.

. A figura da Concessão. In: MEDAUAR, Odete (org,). Concessão de Serviço Público. São Paulo: RT, 1995.

MELlO, Celso Antônio Bandeira de. Curso de Direito Administrativo. 34a ed. São Paulo: Malheiros, 2019.

. Natureza e regime jurídico das Autarquias. São Paulo: RT, 1968.

MENDES, Gilmar Ferreira; BRANCO, Paulo Gustavo Gonet. Curso de Direito Constitucional. $9^{\mathrm{a}}$ ed. São Paulo: Saraiva, 2014.

MINISTÉRIO DO PLANEJAMENTO ORÇAMENTO E GESTÃO. Comissão de Juristas: Proposta de Organização da Administração Pública e das Relações com Entes de Colaboração. Brasília, Secretaria de Gestão, 2007.

MIRANDA, Jorge. Manual de direito constitucional, Tomo IV. $2^{\mathrm{a}}$ ed. Coimbra: Coimbra Editora, 1993.

MOREIRA, Egon Bockmann. Direito das Concessões de Serviço Público: inteligência da Lei 8.987/1995 (Parte Geral). São Paulo: Malheiros, 2010.

NASCIMENTO, Amauri Mascaro; PINHO, Ruy Rebello. Instituições de Direito Público e Privado. $3^{\text {a }}$ ed. São Paulo: Atlas, 1971.

NAVARRO, Thais; SALVADOR, Alexandre; Schelp, Diogo. 30 anos da Constituição: a história da Carta - as origens, os bastidores e a herança do texto que fundou o Brasil democrático. São Paulo: Abril, 2018.

NIMER, Beatriz Lameira Carrico. Moralidade Administrativa. In: BEÇAK, Rubens; NIMER, Beatriz Lameira Carrico; QUINTILIANO, Leonardo David (orgs.). Princípios Constitucionais - Contribuições à Luz da Obra de Sérgio Resende de Barros. Belo Horizonte: Arraes, 2018. 
NOHARA, Irene Patrícia. Burocracia Reflexiva. In: MARRARA, Thiago (org.). Direito Administrativo: transformações e tendências. São Paulo: Almedina, 2014.

OLIVEIRA, Mara Regina de. O desafio à autoridade da lei - A relação existente entre poder, obediência e subversão. Rio de Janeiro: Corifeu, 2006.

PASQUINO, Gianfranco. Governabilidade. In: BOBBIO, Norberto; MATTEUCCI, Nicola; PASQUINO, Gianfranco. Dicionário de Política. Tradução de Carmem Varriale, Gaetano Lo Mônaco, João Ferreira, Luís Guerreiro Pinto Casais. Brasília: Linha Gráfica Editora, 1991.

PEREIRA, César A. Guimarães. Usuários de Serviços Públicos: usuários, consumidores e os aspectos econômicos dos serviços públicos. São Paulo: Saraiva, 2006.

PESSOA, Fernando. Ode Triunfal - Poema de Álvaro de Campos. In: O guardador de rebanhos e outros poemas. $10^{a}$ ed. São Paulo: Cultrix, 1995.

PIRES, Luis Manuel Fonseca. Interesse Público líquido e pós-modernidade: a lógica do individualismo e os desafios do Estado Social no Século XXI. In: MARRARA, Thiago (org.). Direito Administrativo: transformações e tendências. São Paulo: Almedina, 2014.

PRUDENTE, Eunice Aparecida de Jesus. Preeminência Política - Os direitos da Personalidade são Fundamentais. In: AUAD, Denise; OLIVEIRA, Bruno Batista da Costa de (orgs.). Direitos Humanos, Democracia e Justiça Social: uma homenagem à Professora Eunice Prudente: da militância à Academia. São Paulo: Letras Jurídicas, 2017.

QUINTILIANO, Leonardo David. Direitos Sociais e Vinculação do Legislador: as reformas previdenciárias e seus limites no Estado Social e de Direito. Rio de Janeiro: Lumen Juris, 2019.

ROUSSEAU, Jean Jacques. O Contrato Social. Tradução de Antônio de Pádua Danesi. $3^{\text {a }}$ ed. São Paulo Martins Fontes, 1996, p. 25

SARLET, Ingo Wolfgang. Os Direitos Fundamentais na Ordem Constitucional Brasileira. In: ANNONI, Danielle (org.). Os novos conceitos do novo Direito Internacional: cidadania, democracia e direitos humanos. $1^{\text {a }}$ ed., Rio de Janeiro: América Jurídica, 2002.

SILVA, Almiro do Couto e. Os Indivíduos e o Estado na Realização de Tarefas Públicas. In: MARQUES NETO, Floriano de Azevedo, ALMEIDA, Fernando Dias Menezes de, NOHARA, Irene Patrícia, MARRARA, Thiago (orgs). Direito e Administração Pública: Estudos em homenagem a Maria Sylvia Zanella Di Pietro. São Paulo: Atlas, 2013.

SILVA, José Afonso da. Curso de Direito Constitucional Positivo. 42a ed. São Paulo: Malheiros, 2019.

SOUTO, Marcos Juruena Villela. Proteção do Usuário de Serviços Públicos. In: DI PIETRO, Maria Sylvia Zanella, SUNDFELD, Carlos Ari (orgs.). Doutrinas Essenciais: Direito Administrativo, Volume VI: Administração Pública Indireta e Regulação. São Paulo: RT, 2012.

SUNDFELD, Carlos Ari. Fundamentos de Direito Público. $4^{\mathrm{a}}$ ed. São Paulo: Malheiros, 2009. 
TAVARES, André Ramos. Curso de Direito Constitucional. $11^{\mathrm{a}}$ ed. São Paulo: Saraiva, 2013.

Direito Constitucional Brasileiro Concretizado: Hard Cases e soluções juridicamente adequadas. São Paulo: Método, 2006.

TRINDADE, Antônio Augusto Cançado. A humanização do direito internacional. Belo Horizonte: Del Rey, 2006.

\section{TESES E DISSERTAÇÕES}

BEÇAK, Rubens. A Hipertrofia do Executivo Brasileiro: o impacto da Constituição de 1988. 2005. 184 f. Tese (Doutorado em Direito). Faculdade de Direito da Universidade de São Paulo, São Paulo, 2005.

BENTO, Leonardo Valle. Governança e Governabilidade na Reforma do Estado: entre eficiência e democratização. 2002. 246 f. Tese (Mestrado em Direito). - Centro de Ciências Jurídicas, Universidade Federal de Santa Catarina, Florianópolis, 2002.

DEL PICCHIA, Lucia Barbosa. Léon Duguit e a noção de serviço público: elementos para o debate sobre o método no direito público, 2008, $144 \mathrm{f}$. Dissertação (Mestrado em Direito). Faculdade de Direito da Universidade de São Paulo, São Paulo, 2008.

NIMER, Beatriz Lameira Carrico. Ação Popular como instrumento de Defesa da Moralidade Administrativa, 2016, 205 f. Dissertação (Mestrado em Direito). Faculdade de Direito da Universidade de São Paulo, São Paulo, 2016.

MENDES, Conrado Hübner. Deliberative Perfomance of Constitucional Courts. 2011. 278f. Tese (Doutorado em Filosofia). Universidade de Edinburgh, Escócia, 2011.

PEREIRA, Marcelo. O serviço público na atualidade, 1993, 160 f. Tese (Doutorado em Direito). Faculdade de Direito da Universidade de São Paulo, São Paulo, 1993.

PRUDENTE, Eunice Aparecida de Jesus. Direito à personalidade integral - cidadania plena, 126 f., 1996. Tese (Doutorado em Direito). Faculdade de Direito da Universidade de São Paulo. São Paulo, 1996.

QUINTILIANO, Leonardo David. Autonomia Federativa: Delimitação no Direito Constitucional Brasileiro, 2012, 321 f. Tese (Doutorado em Direito). Faculdade de Direito da Universidade de São Paulo, São Paulo, 2012.

\section{CONTEÚDO DISPONÍVEL EM INTERNET}

AGÊNCIA CNI DE NOTÍCIAS. 6 serviços públicos de pior qualidade no Brasil, na opinião da população. Disponível em: https://noticias.portaldaindustria.com.br/listas/6- 
servicos-publicos-de-pior-qualidade-no-brasil-na-opiniao-da-populacao/. Acesso em $15 / 01 / 2019$.

$75 \%$ dos brasileiros dizem que serviços públicos de saúde são ruins ou péssimos, mostra pesquisa da CNI. Disponível em:

https://noticias.portaldaindustria.com.br/noticias/economia/75-dos-brasileiros-dizem-queservicos-publicos-de-saude-sao-ruins-ou-pessimos-mostra-pesquisa-da-cni/.

Acesso em 15/01/2019.

ARAUJO, Vinicius de Carvalho. A conceituação de governabilidade e governança, da sua relação entre si e com o conjunto da reforma do Estado e do seu aparelho. Brasília: Escola Nacional de Administração Pública. 2002. Disponível em:

https://repositorio.enap.gov.br/bitstream/1/661/1/A\%20conceitua\%c3\%a7\%c3\%a3o\%20de $\% 20$ governabilidade $\% 20 \mathrm{e} \% 20$ governan $\%$ c3\%a7a $\% 2 \mathrm{c} \% 20 \mathrm{da} \% 20$ sua $\% 20$ rela\%c3\%a7\%c3 $\%$ a3o $\% 20$ entre $\% 20$ si $\% 20 \mathrm{e} \% 20 \mathrm{com} \% 20 \mathrm{o} \% 20$ conjunto $\% 20 \mathrm{da} \% 20$ reforma $\% 20 \mathrm{do} \% 20 \mathrm{Esta}$ do\%20e\%20do\%20seu\%20aparelho.pdf. Acesso em 02/09/2019.

ARENDT, Hannah. Entrevista concedida para Roger Errera, New York Review of Books, 1974. Disponível em: https://www.google.com/amp/s/amp.scroll.in/article/856549/tenthings-hannah-arendt-said-that-are-eerily-relevant-in-todays-political-times. Acesso em $13 / 01 / 2020$.

BRASIL. Constituição (1988). Constituição da República Federativa do Brasil. Senado, 1988. Disponível em: http://www.planalto.gov.br/ccivil_03/constituicao/constituicao.htm. Acesso em: 07/09/2019.

. Emenda à Constituição Federal n. 19, de 04 de junho de 1998. Disponível em: http://www.planalto.gov.br/ccivil_03/constituicao/Emendas/Emc/emc19.htm. Acesso em: $12 / 06 / 2019$.

. Lei n. 13.460, de 26 de Junho de 2017. Dispõe sobre participação, proteção e defesa dos direitos do usuário dos serviços públicos da administração pública. Disponível em: http://www.planalto.gov.br/ccivil_03/_ato2015-2018/2017/lei/113460.htm. Acesso em: $12 / 06 / 2019$.

BRESSER-PEREIRA, Luiz Carlos. O Modelo Estrutural de Governança Pública. Revista Eletrônica sobre a Reforma do Estado (RERE), 10, 2007. Disponível em: http://www.direitodoestado.con.br/rere.asp. Acesso em 15/07/2018

Reflexões Sobre a Reforma Gerencial Brasileira de 1995. Revista do Serviço Público, 50, 1999. Disponível em:

http://www.bresserpereira.org.br/papers/1999/93ReflexoesSobreRefGerencial.p.pg.pdf.Ac esso em 02 de junho de 2019.

CONFEDERAÇÃO NACIONAL DE INDÚSTRIA. Retratos da Sociedade Brasileira 23 Burocracia. Disponível em: https://bucket-gw-cni-static-cmssi.s3.amazonaws.com/media/filer_public/b2/ab/b2aba791-45fb-47ff-a60d-

14113991ec63/retratosdasociedadebrasileira_23_burocracia1.pdf. Acesso em 02/12/2019.

. Retratos da Sociedade Brasileira 33 - Serviços Públicos, tributação e gastos do governo. Disponível em: https://bucket-gw-cni-static-cmssi.s3.amazonaws.com/media/filer_public/57/89/578911f0-60a8-4048-937a- 
63a3c8312c56/retratosdasociedadebrasileira_33_servicospublicos_tributacao_gastodogove rno.pdf. Acesso em: 02/12/2019.

EL PAÍS. "Há uma desigualdade e injustiça salarial enorme dentro do serviço público". Disponível em:

https://brasil.elpais.com/brasil/2019/11/05/politica/1572980808_559776.amp.html\#referrer =https $\% 3 \mathrm{~A} \% 2 \mathrm{~F} \% 2 \mathrm{Fwww}$. google.com\&amp_tf=Fonte\%3A\%20\%251\%24s. Acesso em 09/01/2019.

MARQUES NETO, Floriano de Azevedo. Ninguém é dono do interesse público. Disponível em: https://www.conjur.com.br/2016-fev-05/estado-direito-ninguem-donointeresse-publico. Acesso em 12/01/2019.

MARRARA, Thiago. O Código de Defesa do Usuário de Serviços Públicos (Lei $n^{o}$ 13.460/2017): seis parâmetros de aplicabilidade. Disponível em: http://www.direitodoestado.com.br/colunistas/thiago-marrara/o-codigo-de-defesa-dousuario-de-servicos-publicos-lei-n-13460-2017-seis-parametros-de-aplicabilidade. Acesso em 16/10/2019.

SANTOS, Boaventura de Souza. Por uma concepção multicultural de direitos humanos. In: Revista Crítica de Ciências Sociais, São Paulo, $\mathrm{n}^{\circ}$ 48, 1997. Disponível em: http://www.boaventuradesousasantos.pt/media/pdfs/Concepcao_multicultural_direitos_hu manos_RCCS48.PDF. Acesso em 26/12/2019

SÃO PAULO (ESTADO). Lei $n^{\circ} 7.835$, de 08 de maio de 1992. Dispõe sobre o regime de concessão de obras públicas, de concessão e permissão de serviços públicos e dá outras providências. Diário Oficial do Estado, São Paulo, SP, 09 de maio de 1992, p.1

Lei $n^{\circ} 10.294$, de 20 de abril de 1999. Dispõe sobre a proteção e defesa do usuário do serviço público do Estado. Diário Oficial do Estado, São Paulo, SP, 21 de abril de 1999, p.2.

SÃO PAULO (MUNICÍPIO). Decreto $n^{\circ} 58.426$, de 18 de setembro de 2018. Regulamenta a Lei Federal $n^{o}$ 13.460, de 26 de junho de 2017, dispondo sobre a atuação dos responsáveis por ações de ouvidoria e a participação, proteção e defesa dos direitos do usuário de serviços públicos; transfere a Coordenadoria de Defesa do Usuário do Serviço Público Municipal - CODUSP para a Controladoria Geral do Município; institui a Política Municipal de Atendimento ao Cidadão, no âmbito da Cidade de São Paulo; revoga os dispositivos que especifica. Diário Oficial da Cidade de São Paulo, São Paulo, SP, 19 de setembro de 2018, p.1.

UNIÃO EUROPÉIA. Versões Compiladas do Tratado da União Europeia e do Tratado que institui a Comunidade Europeia (2002). Disponível em: https://eurlex.europa.eu/legal-content/PT/TXT/PDF/?uri=CELEX:12002M/TXT\&from=PT. Acesso em $02 / 12 / 2019$. 